\title{
Specific Delayed-type Hypersensitivity Footpad Response in Mice Artificially Immunized with Two Trypanosoma (Schizotrypanum) Species
}

\author{
By A. J. LISTON, J. R. BAKER AND LINDA F. SELDEN \\ Medical Research Council Biochemical Parasitology Unit, \\ Molteno Institute, Downing Street, Cambridge CB2 ${ }_{3} E E$
}

(Received I6 September I976; revised I5 October 1976)

\section{INTRODUCTION}

There is much evidence that $\mathrm{T}$-cell (thymocyte) mediated immunological responses occur in patients or laboratory animals infected or artificially immunized with Trypanosoma (Schizotrypanum) cruzi (see review by Hanson, 1976). As part of a study of species of this subgenus which do not infect man, we investigated the specificity of a cell-mediated immune response in mice artificially immunized with $T$. (S.) dionisii or $T$. (S.) vespertilionis (of Chiroptera), using as an indicator the delayed hypersensitivity footpad skin test (Crowle, 1975). Some preliminary work has been reported (Liston, 1974).

\section{METHODS}

Origin and maintenance of strains. Trypanosoma $(S$.) dionisii strain P3 and $T$. $(S$.) vespertilionis strain N6, isolated from Pipistrellus pipistrellus and Nyctalus noctula respectively (Baker \& Thompson, I97I) were maintained as frozen $\left(-196{ }^{\circ} \mathrm{C}\right)$ stabilates and in vitro at $28{ }^{\circ} \mathrm{C}$ in medium L4NHS (medium L4N of Baker et al., 1972, with halved concentrations of rabbit serum and rabbit erythrocyte lysate).

Immunization of mice. Adult male Parke's mice (Animal Virus Research Institute, Pirbright, Surrey) were immunized with two intradermal injections, 2 weeks apart, of $0.05 \mathrm{ml}$ of one of the following three preparations: 5 -day-old cultures of (i) $T$. dionisii or (ii) T. vespertilionis, washed three times and resuspended in phosphate-buffered saline, $\mathrm{pH} 7 \cdot 3$ (PBS; Dulbecco's solution A, Oxoid) at $4 \times 10^{8} \mathrm{ml}^{-1}$ and emulsified with an equal volume of Freund's complete adjuvant (FCA; Difco), so that each mouse received $\mathrm{I} \times 1 \mathrm{I}^{7}$ flagellates; or (iii) culture medium L4NHS emulsified with an equal volume of FCA.

Preparation of antigen. Purified soluble antigen (PSA) for skin testing was prepared from cultures of $T$. dionisii and $T$. vespertilionis as described by Bryceson et al. (1970), freeze-dried and stored at $-20{ }^{\circ} \mathrm{C}$; it was reconstituted at $\mathrm{I} \cdot 0 \mathrm{mg} \mathrm{ml}^{-1}$ in PBS.

Skin testing. Groups of immunized or normal mice (see above) were inoculated intradermally in the plantar surface of the hind feet with 0.0I ml PBS or PSA, with the aid of an Agla micrometer syringe (Wellcome), 4 weeks after the first immunizing injection. The thickness of the foot was measured immediately before, and at intervals after, this procedure, with a Quicktest model AozT gauge (Carobronze Ltd, School Road, Belmont Road, London W4). All experiments were conducted 'blind', the person measuring the response not knowing which immunogen, if any, had been given to a mouse, nor which foot had received antigen or control PBS. 


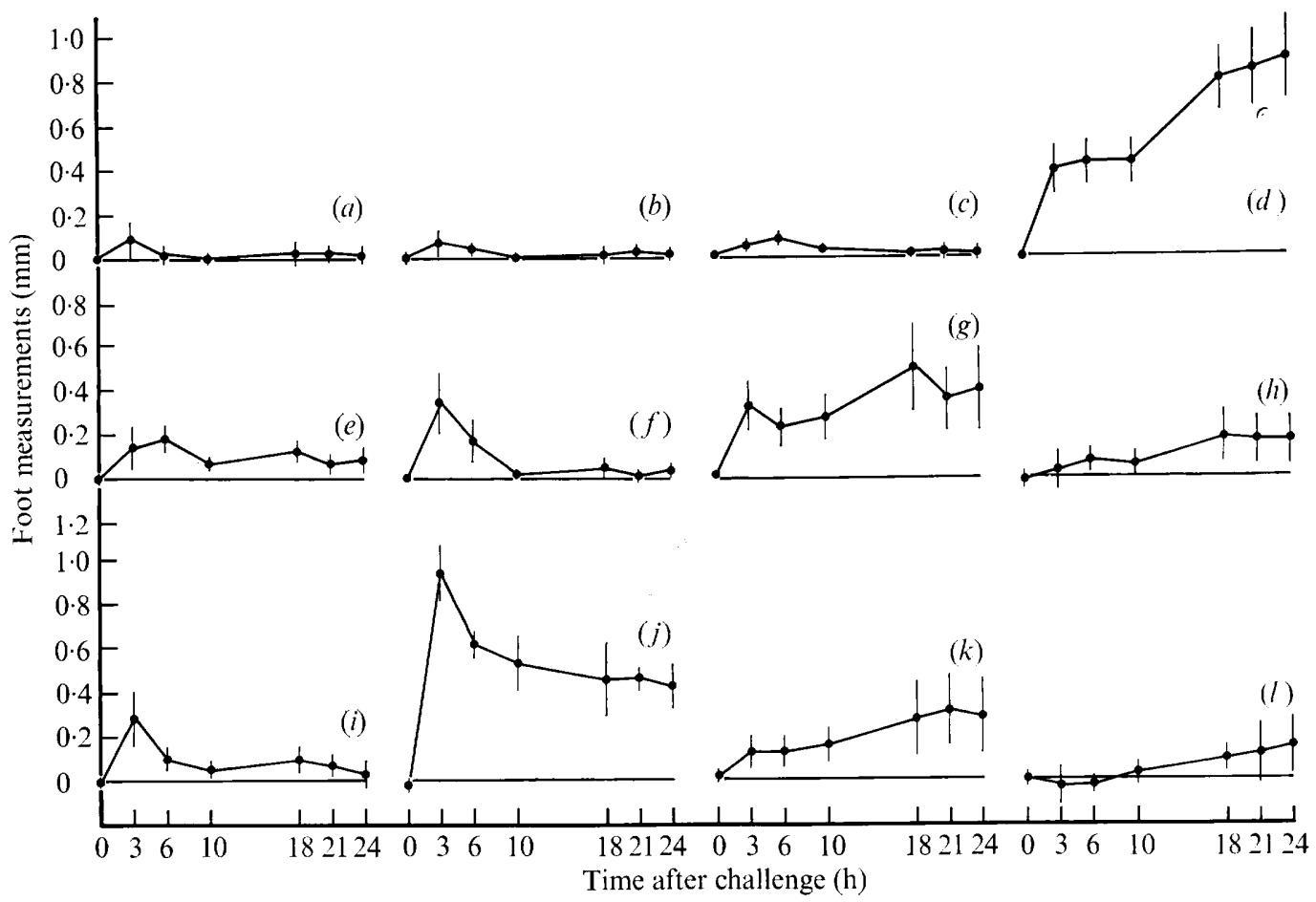

Fig. I. Skin test reactions of mice challenged intradermally in the footpad with $0.01 \mathrm{mg}$ antigen or 0.or $\mathrm{ml}$ culture medium $\mathrm{L}_{4} \mathrm{NHS} 4$ weeks after the first of two immunizing injections ( 2 weeks apart) of $10^{7}$ trypanosomes or $0.025 \mathrm{ml}$ medium in Freund's complete adjuvant given intradermally. The experiments were performed 'blind' (see Methods). Each point represents the mean difference in thickness between the foot challenged with antigen and that of the same mouse receiving PBS only, measured in millimetres at the time shown. Vertical bars show $95 \%$ confidence limits (twice the standard error of the mean); the difference in thickness is significant at this level when the bars do not meet the line indicating zero difference.

\section{Immunogen}
(a) None
(b) None
(c) None
(d) T. dionisii $\mathbf{P} 3$
(e) T. dionisii $\mathbf{P} 3$
(f) $T$. dionisii $\mathbf{P} 3$

$$
\text { Challenge No. of }
$$$$
\text { antigen mice }
$$

$\begin{array}{ll}\text { T. dionisii } \mathbf{P} 3 & 2 \mathrm{I} \\ T \text { vespertilionis N6 } & \mathrm{I2}\end{array}$

$T$. vespertilionis $\mathrm{N} 6 \mathrm{I} 2$

Medium L4NHS II

$\begin{array}{ll}\text { T. dionisii } \mathrm{P} 3 & 29\end{array}$

$T$. vespertilionis N6 18

Medium L4NHS 22
Immunogen

(g) T. vespertilionis N6

(h) T. vespertilionis N6

(i) T. vespertilionis $\mathrm{N} 6$

(j) Medium L4NHS

(k) Medium L4NHS

(l) Medium L4NHS Challenge
antigen $\begin{gathered}\text { No. of } \\ \text { mice }\end{gathered}$

$T$. vespertilionis $\mathrm{N} 6 \mathrm{I} 6$

T. dionisii $\mathbf{P} 3 \quad \mathbf{I} 2$

Medium L4NHS 12

Medium L4NHS 4

T. dionisii $\mathrm{P} 3 \quad \mathrm{I} 3$

T. vespertilionis $\mathrm{N} 6 \quad 6$

\section{RESULTS AND DISCUSSION}

No delayed response significantly greater than that occurring in the footpad challenged with saline resulted from challenging non-immune mice with either trypanosomal or medium antigens (Fig. I $a, b, c$ ), nor did any delayed response occur in mice immunized with FCA and challenged with either trypanosomal antigen or medium.

Strong, highly significant $(P<0.05)$ delayed responses occurred in mice immunized with trypanosomal antigen or medium and challenged with homologous antigen (Fig. $\mathrm{I} d, g, j$ ).

Slight but significant delayed cross-reactions occurred in mice immunized with $T$. dionisii and challenged with $T$. vespertilionis (Fig. I $e$ ) and in the reciprocal test (Fig. I $h$ ), indicating that the two species possessed some shared antigens. Other workers have shown the existence 
of common antigens within the subgenus Schizotrypanum: Bice \& Zeledón (1971) showed electrophoretically that $T$. cruzi and a Costa Rican strain identified as $T$. vespertilionis shared five out of seven antigenic fractions and Soria \& Dusanic (1975) demonstrated by immunodiffusion the existence of shared and specific antigens in the strains of $T$. dionisii and $T$. vespertilionis used by us; such antigens were not, however, necessarily those responsible for delayed hypersensitivity skin reactions.

Similar cross-reactions occurred in mice immunized with $T$. vespertilionis and challenged with medium (Fig. $\mathrm{I} i$ ), in the reciprocal test (Fig. $\mathrm{I} l$ ) and in mice immunized with medium and challenged with $T$. dionisii (Fig. I $k$ ); these were probably caused by contamination of the trypanosomal antigen by endocytosed medium. Mice immunized with $T$. dionisii and challenged with medium did not give a delayed response (Fig. I $f$ ), possibly because $T$. dionisii, a smaller organism in vitro than $T$. vespertilionis, contained after washing only traces of medium which were insufficient to provoke an immune response after challenge with medium; mice immunized with medium in the reverse reaction would be highly sensitized to the very immunogenic medium components so that traces of medium in the $T$. dionisii challenge antigen could produce a response.

These results, which showed a considerable degree of specificity of the delayed response, and those of Soria \& Dusanic (1975), indicated some, thoughincomplete, antigenic difference between $T$. dionisii and $T$. vespertilionis. Immediate responses were less specific but the homologous reactions were more pronounced.

We thank Mr D. E. Walters, ARC Statistical Unit, Department of Applied Biology, University of Cambridge, for advice and the Ministry of Overseas Development for financial support.

\section{REFERENCES}

Baker, J. R. \& Thompson, G. B. (197I). Two species of Trypanosoma from British bats. Transactions of the Royal Society of Tropical Medicine and Hygiene 65, 427.

Baker, J. R., Green, S. M., Chaloner, L. A. \& GaboraK, M. (1972). Trypanosoma (Schizotrypanum) dionisii of Pipistrellus pipistrellus (Chiroptera): intra- and extra-cellular development in vitro. Parasitology 65, 25I-263.

BICE, D. E. \& ZELEDón, R. (I971). Immunoelectrophoretic comparison of Trypanosoma vespertilionis and Trypanosoma cruzi. Revista de biologia tropicale 19, I49-152.

Bryceson, A. D. M., Bray, R. S., Wolstencroft, R. A. \& Dumonde, D. C. (1970). Immunity in cutaneous leishmaniasis of the guinea-pig. Clinical and Experimental Immunology 7, 30I-34I.

Crowle, A. J. (1975). Delayed hypersensitivity in the mouse. Advances in Immunology 20, 197-264.

Hanson, W. L. (1976). Immunology of American trypanosomiasis (Chagas' disease). In Immunology of Parasitic Infections, pp. 222-234. Edited by S. Cohen and E. H. Sadun. Oxford: Blackwell Scientific Publications.

Liston, A. J. (1974). Cell-mediated immune responses in mice to trypanosomes of the subgenus Schizotrypanum. Transactions of the Royal Society of Tropical Medicine and Hygiene 68, 6.

Soria, C. A. \& DusANIC, D. G. (1975). Comparative studies of Trypanosoma vespertilionis Battaglia and Trypanosoma dionisii Bettencourt \& França. Journal of Protozoology 22, 509-513. 